Session 1365

\title{
Mathematics Requirements on a Computer Technology Unit
}

\author{
D Veal, S P Maj, G.I. Swan \\ Computing Science / Computing Science /Physics Program \\ Edith Cowan University (ECU). Perth. Western Australia
}

\begin{abstract}
Computer Installation \& Maintenance (CIM) is a 'hands on' unit run by the Computing Science department at Edith Cowan University (ECU). CIM was designed and introduced as a direct result of an analysis of job advertisements in newspapers in Western Australia and interviews with potential employers in the field of computer and network installation and maintenance. This first level unit consists of a weekly two-hour lecture with an accompanying tow-hour 'hands on' workshop, and does not have any mandated entrance prerequisites and yet CIM attracts a wide range of students, has been consistently oversubscribed, and attracts both cross-faculty and cross-institutional enrolments from other universities within the Perth area. Its wide appeal across a broad spectrum of students has meant that many of those who enrol may not possess an appropriate technological, scientific, and mathematical background. Hence a new pedagogical framework was required. However led to the use of a model required that students to be able to solve simple formulae, convert to and from SI magnitudes and to transpose simple equations. The need for basic mathematical skills and knowledge is considered as many students found the above mathematical requirements problematic. The testing of students' mathematics on this unit, the results, and the reasons for the response chosen to address these problems along with the necessary mathematics required on this unit, are outlined.
\end{abstract}

\section{Introduction}

Computer Installation \& Maintenance (CIM) and are 'hands on' units run by the Computing Science department at ECU. This unit was designed and introduced as a result of surveys of job advertisements in papers in Western Australia. Subsequent interviews with potential employers in the computer and network support who had recently advertised for staff lead to a list of employer requirements. Testing of $10 \%$ of third year computer science students, who had successfully passed all of their previous units, subsequently revealed that none could fulfil these requirements ${ }^{14}$. Those who could partly fulfil the employer requirements had been self-taught. International studies have revealed that a similar situation also exists in other countries ${ }^{14}$. Similar findings were discovered from testing multi-media students ${ }^{15}$. CIM is a single semester first level unit. It consists of a weekly two-hour lecture with an accompanying two-hour 'hands on' workshop.

Proceedings of the 2001 American Society for Engineering Education Annual Conference \& Exposition Copyright C 2001, American Society for Engineering Education 
During the CIM workshop students perform a set of tasks such as installing and testing hard drives, network cards, video cards, upgrading memory and simple faultfinding exercises. The CIM unit is an option within the ECU computing science degree requirements however it is a full credit unit. This unit has consistently been oversubscribed and attracts students both from other faculties within ECU and from other universities within the Perth area. Students on this unit have included IS management students, Multi-media students, ${ }^{11}$ as well as students studying dance and drama. The lack of any mandated perquisites may have helped to widen the appeal of the CIM unit in attracting a broad range of students ${ }^{22}$.

\section{Constructivism}

As the CIM unit had no prerequisites it is necessary to proceed from the assumption that students had no previous computer hardware technology education. Constructivism suggests the starting point for the explanations was the student's own experiences. A top down approach was used rather than proceeding from basic electronics concepts upwards ${ }^{16}$. For example storage and throughput requirements are made initially from concepts such as files, and filing cabinets are equated with computer secondary memory. Freeways and slower roads are compared to computer buses and slower data paths within a computer. Students also note the changes wrought by upgrades and check these changes against expectations based on bandwidth considerations.

This is in line with parts of Constructivist theory that is based upon enabling students to build increasingly complex scaffoldings of understanding upon their current scaffolding. The Zone of Proximal Development, (ZPD) which is the phase at which a task can be mastered given appropriate support. ${ }^{24}$ Benson notes that "Vygotsky ${ }^{23}$ claimed that the larger the zone the better students will learn in school" ${ }^{2}$ Matching leaning tasks within student's ZPD is an important part of the teaching process from a constructivist viewpoint.

\section{The B-Node Model}

A new pedagogical model has been developed to enable students to compare and contrast PCs with different internal components using bandwidth nodes. Bandwidth or throughput calculations were seen as an important in enabling students to assess whether a computer has the appropriate hardware configuration to handle a particular job. The underlying measure of bandwidth enables a minimum performance criterion that is independent of the underlying technological implementation ${ }^{16}$. Likely bottlenecks can be detected found via a sequence of B-Nodes where obvious 'weak links' can help highlight potential problems.

B-Node models are independent of the basic underlying technological implementation. This is analogous to the use of digital logic gates symbols. Digital logic gates may be based on electromagnetic relays, thermionic valves (or tubes), discrete transistors, or silicon chips. Hence using the B-Node model means that students do not to relearn the underlying digital electronics for every major change in technology. Such methods could be especially useful for multimedia and business studies students. B-Node analysis is achieved via calculations of throughput or bandwidth. However, this requires that students are able to solve the 
associated mathematics. From the results of a student questionnaire 37 out of 40 students thought that B-Nodes should be taught on the CIM unit. ${ }^{16}$. A significant advantage of the BNode model is that simple and meaningful diagrams can be used. Circuit diagrams, even at the chip level, can be confusing for students with little previous technological education.

4. Student Difficulties on the CIM unit with basic Mathematics

Staff on the CIM unit noted that students were having difficulties with basic mathematics in particularly in the area of bandwidth calculations and number base conversions. Particular problems included:

1. Rounding, significant figures and decimals places.

2. Estimation ("Ball park" figures to detect obvious errors)

3. Standard scientific notation in particular, and indices in general.

4. Binary, hexadecimal to denary conversions.

5. Simple transposition of formulae.

6. Derivation of a result given facts about the storage or transmission rates of data.

7. Being able to solve problems using appropriate formulae.

8. S.I. units. Appropriate use of SI magnitudes such as Giga, Mega, nano etc.

These findings were in line with the findings of Armstrong and Croft who noted that: "Many entrants to undergraduate mathematics dependant programmes are being disadvantaged because they lack sufficient skill in basic mathematical techniques". And that : "University tutors should not assume that all their students have wide-ranging basic knowledge and skills in mathematics" ${ }^{1}$.

The following example illustrates the type of calculation that students are required to undertake. It should be noted that the concept of bandwidth used here is bits or Bytes per second and not Hertz or Mega Hertz from Telecommunications theory.

"Bandwidth $=$ Clock $x$ Data Path Width $x$ Efficiency. The early Intel 8088/86 required a memory cycle time of 4 clocks cycles (Efficiency $=1 / 4$ ) however, for the Intel $80 x 86$ series, including the Pentium, the memory cycle time consists of only 2 clocks $($ Efficiency =1/2) for external DRAM (Results, 1999). A 100Mhz Pentium, with a data path of 8 bytes has a therefore bandwidth of $400 M b y t e s / s^{\prime \prime}{ }^{17}$.

In regard to performing such calculations it was implicitly assumed by staff on the CIM unit. However, the assignment and examination results strongly indicated this was not the case for a significant number of unit participants.

\section{The Bandwidth Calculation Test}

In order to quantify potential difficulties in performing bandwidth calculations by students, a short test was given. This involved the use of scientific notation, Units, significant figures, the use of basic formulae and SI magnitudes. A total of 46 students took part, which was

Proceedings of the 2001 American Society for Engineering Education Annual Conference \& Exposition Copyright C 2001, American Society for Engineering Education 
approximately $50 \%$ of the students on the CIM unit. The mean mark was $60 \%$ however as the test was designed to also test very basic calculations this result meant that there was a significant problem with regard to many student's mathematical skills and understanding in the areas covered by the test. The test was given to students before such topics were introduced in lectures to help to ascertain their knowledge and skills on entry into the unit. Only $31 \%$ of students tested could successfully state how many nanoseconds there were in a millisecond. Less than $30 \%$ could correctly state the number of bits in a Gigabit and only $15 \%$ could perform the necessary calculations to convert a periodic time to a frequency and frequency to a bandwidth measured in bits per second. However, $67 \%$ could correctly convert 1000 bytes per second into bits per second. Many students did not appreciate ideas of significant figures; others experienced problems with substitution or the choice of an appropriate equation. The students' calculations of bandwidth were noted, these involved converting between time periods and frequencies; frequencies to bits per second and bytes per second; multiplying the bandwidth for one line with the number of lines used to carry the data. Again many students experienced difficulty in converting between S.I. magnitudes. CIM students also require algebraic substitution and formula selection skills to assess whether particular power supplies were sufficient to handle the power requirements at particular output voltages. It can be concluded that most students had insufficient mathematical skills to enable them to benefit fully from their participation in the CIM unit. It was then decided to investigate possible methods to help overcome this problem.

6. Possible solutions to the lack of basic maths skills

In order to attempt address the problem of lack of basic maths skills amongst many of the students on the CIM unit the following possibilities were considered:

1. A short maths unit.

2. Extra basic maths practice as part of lectures.

3. Extra basic maths practice as part of the workshops.

4. The use of Pre-recorded Material

5. The use of a computer based tutorial either via CDROM for pre-recoded tutorials, or via the web.

6. A drop-in Maths surgery.

\subsection{A Short Maths Unit}

A similar problem had arisen in respect to the possibility of an extra physics unit. It had also been discovered that students on the CIM unit lacked basic physics skills via a simply physics test and questionnaire ${ }^{25}$. Asked whether they would like an extra basic maths unit most students replied that they did not wish to undertake an additional unit to help rectify this situation. This was due to:

1. The extra cost involved.

2. Not being able to fit in the lectures due to extra time available.

3. Not wanting to become involved in yet more study.

Proceedings of the 2001 American Society for Engineering Education Annual Conference \& Exposition Copyright (C) 2001, American Society for Engineering Education 
It was thought likely that a similar result would result in this case and so the question was not asked.

6.2 Extra basic maths practice as part of lectures.

As an additional part of the lectures there would be very little chance for staff to deal with individual problems as they arose. Furthermore, the quantity of detail covered by these lectures, partly due to the necessity of covering much of the background from a perspective of no previous technical knowledge, means that there is little or no time available for extra material.

6.3 Extra basic maths practice as part of the workshops.

Considerable time, effort and expense had gone into securing the workshop rooms faculties and maintenance support of two hour for each CIM workshop. This was in addition to the initial setting up and taking down periods at the start of a weekly series of sessions. If much of this time was to be spent in maths work then this could have been seen to use most of the time in such expensive workshops as not requiring these extra facilities.

However, there was often some time available near the end or after such sessions. The time at the end as due to the fact that not all workshops took the same time and yet the longest was designed not to exceed the two-hour limit. The time after the workshop was available, as it would not otherwise be used, as there was a two hour checking and resetting time allowed for the technical staff to prepare for the next workshop. However, with some of the longer workshop session some students may need to take the full two hours normally available and the proposed extra maths practice could reduce the time available to spend on the practical exercises.

\subsection{Pre-Recorded Tutorials}

These could include sound recorded sections talking students through the more difficult exercises and notes. An advantage of such an approach is that most students have ready access to a tape recorder. A major disadvantage is that it is not interactive. The Open University (OU) in the UK often used this approach. On some OU units the use of taped recorded audio as well as video instruction included self assessed questions as well as the use of reading material. However due to the both the size of the student base for many of the OU Units and the ability of this university to spend many staff hours for each student hour spent studying it was not felt to be an effective use of staff time to attempt develop such a system.

\subsection{Computer-Based Tutorials}

The computer based tutorial was not felt to be a possibility or from a staff point of view the development of Computer Based Learning (CAL) materials was considered to represent a large input of extra effort that could be better spend in developments with respect to these units. However there are many commercially available packages that could have been of use.

Proceedings of the 2001 American Society for Engineering Education Annual Conference \& Exposition Copyright C 2001, American Society for Engineering Education 
However cost and time constraints have initially limited investigation of these packages on the CIM and NIM units.

Caccetta et el have noted that: "The problems encountered in teaching first year mathematics are not unique to Australia. Universities worldwide are utilising computer assessed learning to help overcome the problems". They further note that: "Computer technology can be used both for diagnostics and for supplementary material for a unit" "

In a study of the use of a computer based tutorial system be Faye and Scott students noted that: "The main advantage of the computer based tutorial in the students opinion was that the you could work at their own pace and the deadlines and strict monitoring forced students to complete work and stay up-to-date". They also mentioned the "the ability to obtain help quickly" ${ }^{6}$. Whilst Roisin Donnelly and Gorman have noted that:

"Each student can work at an appropriate level of difficulty and proceed in the lesson at a pace that is appropriate for them. Such individualised instruction is a significant feature of $C A L$ " However, they go on to note: "The major weakness of the computer based tutorial identified by the students was the lack of help needed to make conceptual jumps and for understanding a concept thoroughly". Interestingly they found that: "While students felt comfortable in asking questions in both tutorials they were more comfortable asking questions in the computer-based tutorials" ${ }^{20}$.

Further research in developing maths multi-media tutorials in higher education by Harding, Lay and Moule noted the importance of being able to alter the sequence of student's viewing of material to encourage exploratory learning. This meant that the materials were arranged in small blocks ${ }^{8}$. The courseware was designed to be used across a range of curricula and they note that video and sound clips can now be readily included thus gaining many of the advantages of pre-recorded materials as noted above. They also noted the importance of being able to provide a 'kit of parts' that "individual teachers can take apart and reassemble in the order they wish" ${ }^{8}$.

\subsection{A Drop-in Maths Surgery}

Armstrong notes that at Loughbourgh University "Drop in surgeries are open to all engineering students four afternoons and one evening each week during term time. ${ }^{1}$. Such surgeries can also expand the tutor's experiences with an extremely diverse range of students seeking help. The first author found when helping to run such a surgery in a further education college in the UK, that the problems brought to his attention in the same session ranged from basic addition and subtraction to $2^{\text {nd }}$ order partial differential equations. There was also a large variation in the usage patterns of this surgery by students. Some students would just come into the surgery as needed and leave when they had found how to solve particular types of problems. Other students would regularly attend each week and would work through exercises in the surgery and seek help if and when problems that they were unable to solve on their own.

Proceedings of the 2001 American Society for Engineering Education Annual Conference \& Exposition Copyright C 2001, American Society for Engineering Education 
A drop-in maths surgery would have needed to be a faculty, or campus wide, initiative. This would have required extra resources and reallocation of staff commitments within a short time frame, which may well have not been possible under the present prevailing circumstances. Furthermore with 50\% of undergraduate assessment being via assignment, care would need to be undertaken to ensure that this facility was not used for answering assignment questions.

\section{The delivery method chosen}

It was therefore concluded that each potential method of delivery of the basic maths theory and practice had its strong and weak points. From a practical short term feasibility perspective the mathematics was delivered via a short session at the start of the workshop period. A requirement was that this should not take up more than twenty minutes at most of the two-hour workshop. As much as was feasible the maths work was in the context of the work in the lectures and the practical session. However, some maths work had to commence well before the use of the topic in the lectures due to the time needed for the students to gain familiarity with the subject matter. For the workshops, where it was thought that students would need most of the session to complete the practical work, the mathematics component was significantly reduced.

Initially during the maths section of the workshop periods, examples of binary and hexadecimal and denary conversion and their practical uses was undertaken. Then work on estimation, and significant figures was attempted. Exercises in scientific notion and conversions to and from SI magnitudes were given. Bandwidth calculations standing with basic time period to frequency calculations and bit to byte Megabyte and Gigabyte calculations were shown. Students then attempted to solve these problems in the tutorial group and simple transpositions of formulae. Although important, merely using drill and practice was regarded as insufficient and all problems were all given in the context of units and involved calculations that would be used in computer and network support. Problems, such as bandwidth calculations, were used to check on the minimum throughput requirements of PCs and could be used to compare and contrast some of the strengths and weaknesses of actual computer systems. The use of equations was demonstrated in situations likely to arise in the CIM unit.

The assignment results for the unit indicated that there was a significant improvement in student's abilities to calculate bandwidth compared with those of the previous year before the implementation of the extra basics maths teaching and practice. However this was not always the case as a minority of students were still not able to successfully perform the bandwidth calculations exercises. These students appeared to have problems in deciding what parts of the data in a given hardware specification to utilise in their calculations. A possible way of flagging such difficulties could be to give example questions as homework during one tutorial and show solutions during the following tutorial hence giving students a week to work on the problem and then checking student's progress. It should be noted that those who were experiencing difficulty during the tutorials had the opportunity to stay behind after the

Proceedings of the 2001 American Society for Engineering Education Annual Conference \& Exposition Copyright (C) 2001, American Society for Engineering Education 
tutorial or could ask to see the tutor later, for extra examples and practice. However it was mostly the mature aged students who chose to attend these extra sessions.

8. Are there Fundamental Mathematical Requirements for School Leavers?

The problems encountered with students' level of basic mathematics on the CIM unit pose the following questions, which are a part of many basic maths debates:

1. What standard of basic mathematics should students possess on leaving school?

2. Should the main concentration in school maths education be on a practical sense or on an appreciation of the subject of mathematics?

However Keitel has noted that:

"Mathematics teaching can no longer be perceived as a bound to a model of transmission or broadcasting. New perspectives for the teaching and learning processes have to be developed, such as those offered by constructivist theory or the psychology of contentrelated activity. A dynamic view of mathematics and the teaching and learning of mathematics must replace the existing conception of mathematics as a series of compartmentalized tasks and prescribed actions".

Keitel goes on to state that: "Applications and structural insight, technological and systemic aspects are no longer regarded as contradictory aspects of mathematics education, as they were in some reform debates" ${ }^{10}$. Furthermore, there have been many complaints internationally about students' deficiencies in basic mathematics ${ }^{3}$. Whilst McHenry has noted with respect to the quantitative understanding, that "It is clear that this need for a workforce able to think quantitatively is much more of a challenge to school mathematics, science and engineering than the nurturing of the best students toward careers in mathematics, science and engineering" ${ }^{17}$. Maybe these approaches need not be mutually exclusive. A major challenge for today's education systems are to be able to effectively serve a broad cross-section of student needs in the areas of mathematics, science, and technology. McHenry has also noted with respect to the lack of quality mathematics education reaching the broad mid-range of students: "without such an outcome, the student must seek the opportunity of remedial mathematics education in college, trade school, or on the job. None of these is particularly satisfactory, ..." 17 . Magrid, in an article entitled "America's real skills shortage" makes the point that maths is one part of a collection of basic skills increasingly required in the modern workplace: "When thinking about future jobs, its important to focus on the basic skills of reading, writing and math, as well as increasingly important skills such as critical thinking and public speaking”. ${ }^{13}$.

However, deficiencies in mathematics can be seen as a wide-ranging problem from basic maths skills to mathematical understanding at a higher level such as amongst full time students in engineering faculties. Kumar notes "It is the widespread opinion and belief among engineering faculty that undergraduates enrolled in any engineering field could be better prepared in mathematics when taking courses related to their professional field of

Proceedings of the 2001 American Society for Engineering Education Annual Conference \& Exposition Copyright C 2001, American Society for Engineering Education 
study" ${ }^{12}$. In respect to students' basic skills and knowledge requirements Goldsmith and Mark note the need for mathematical literacy and that:

"Literacy involves understanding mathematical principles; developing mathematical ways of thinking; and acquiring fluency with number, geometry and data. Students develop this literacy by activity doing mathematics, using their skills and knowledge to solve problems and to investigate mathematical ideas" 7 .

However, there are problems with the notion of mathematical literacy. Pugalee notes that: "Both in the United Sates and abroad, the task of creating a coherent vision of what it means to be mathematically literate has not been sufficiently realised" ${ }^{18}$. Whilst Confrey notes that the call for an understanding of mathematics to prepare students to take part in technological based occupations different from those made previously:

"The call is for a technological workforce, and this call to my mind differs form either of the previous mandates those prepared to the preparation of mathematicians or to improving standards to create a quantitatively literate public". Confrey also notes that "this obligates us to view mathematics as fundamentally a tool" 5.

Mathematics is used as a tool on the CIM unit and this is basically the approach that is taken. The aim on these units is not to provide a general understanding of basic mathematics, but to use only specific parts of the subject as necessity dictates. However, a higher level of mathematical literacy attainment by students enrolling on the units would, no doubt, help their understanding of some of the subject matter. No doubt this debate will continue. Students' motivation to learn mathematics can be of vital importance in the learning process, and when they is perceived as relevant to their needs, as on the CIM unit, they can be prepared to undertake the extra work and effort required.

\section{Conclusions}

Two new units were introduced based upon job advertisements, employee requirements. The teaching of mathematics was certainly not a part of the original intention of these units. However, due to a lack of basic mathematics skills amongst many of the students involved, it was found necessary to include some mathematics tuition as part of the unit. Basic mathematics was found to be an essential requirement of this technological based study. With these non-perquisite units extra mathematics practice was required to enable some to appreciate the numerical aspects presented in this unit. Such mathematics was also necessary to enable students to gain the understanding to successfully complete their assessed work and to be able to apply such skills in possible future employment.

The use of computer hardware maths based modeling and calculation necessary for this unit could be undertaken from a converse direction by using 'hands on' experiences with computer hardware to demonstrate vocationally relevant uses of mathematics.

Proceedings of the 2001 American Society for Engineering Education Annual Conference \& Exposition Copyright C 2001, American Society for Engineering Education 


\section{Biliograhy}

1. Armstrong, P. K. \& Croft, A. C. Identifying the Learning Needs in Mathematics of Entrants to Undergraduate Engineering Programmes in an English University. European Journal of Engineering Education Vol 12 No 1 European Society for Engineering Education. 59-71, 1999.

2. Benson, A. Review and Analysis of Vygotsky's Thought and language. 1995.

URL: http://www.129.7.160.115/inst5931/Vygotsky.htm

3. Bird, D \& Hiscox, M. Mathematics and Employment: a study of liaison activities. Schools Council Working Paper 68. Methuen Educational. London. U.K. 9-12, 1981.

4. Caccetta, L. Hollis, P. Slew, P. F. \& White, B. Strategies for assisting the transition from secondary to tertiary mathematics. Proceedings of the $6^{\text {th }}$ Annual Teaching and Learning Forum. Murdoch University Perth Western Australia. 62 -67, 1997.

5. Confrey, J. Changing from preparing only mathematicians to educating for a technologically advanced workforce: Are we ready, willing... and able? Proceedings of the 1997 Australian Association of Mathematics Teachers Conference. Melbourne. Australia, 1997.

6. Faye, C. \& Scott, N. W. Cost-effective computer-based tutorials. Proceedings of the 1998 American Society for Engineering Education Conference. Seattle, Washington, USA. 1998.

7. Goldsmith, L. T. \& Mark, J. What Is a Standards-Based Mathematics Curriculum? Educational Leadership. Vol 57 No3 40-44, 1999.

8. Harding, R. D. Lay, S. W. \& Moule, H. Lessons in Developing Mathematical Courseware. Journal of Computing in Higher Education. 7(1). 3-32, 1995.

9. Heyward, J. Assessment in Higher Education. 2ed. John Wiley \& Sons. Chichester. 222- 225, 1989.

10. Keitel, C. Is there a real Chance for "Mathematics and Science for All Americans"? Proceedings of the University of Chicago School Mathematics Project International Conference on Mathematics Education. National Council of teachers of Mathematics. USA. 35-48, 1992.

11. Kohli, G. Maj S.P. \& Veal, D. Multi-media technology - an opportunity for modern engineering education. ASEE Conference. St. Louis, MO. USA. 2000.

12. Kumar, S. \& Jalkio J. Teaching Mathematics from an Applications Perspective. Proceedings of the 1998 conference American Society for Engineering Education. Seattle, Washington, USA. 1998.

13. Madgid, L. America's real skills shortages. InformationWeek Feb $2^{\text {nd }}$. MA. USA. 1998.

14. Maj, S. P., Robins G., Shaw, D. \& Duley, K. W. Computer and Network Installation, Maintenance, and Management - A Proposed New Curriculum for Undergraduates and Postgraduates. The Australian Computer Journal, 30(3). 1997.

15. Maj, S. P., Kohli, G., \& Veal, D. Teaching Computer and Network Technology to Multi-Media students - a novel approach. The 3rd Baltic Region Seminar on Engineering Education, Goteborg, Sweden. 1999.

16. Maj, S. P. Veal, D. \& Charlesworth, P. Is Computer Technology Taught Upside Down? 5th Annual Conference on Innovation and Technology in Computer Science Education, Helsinki, Finland, 2000. Sponsored by ACM. SIGCSE. 2000 .

17. McHenry, K. W. Mathematics Education: An Industrial View. In Proceedings of the UCSMP International Conference on Mathematics Education. Developments in School Mathematics Education Around the World. (1991). Vol 3 National Council of Teachers of Mathematics. Reston VA. USA. 14-23. 1992.

18. Pugalee, D. K. The Clearing House. Vol 73 No1 Gale Group. 19-21. 1999.

19. Results T. W. and. Results, L. B.. The Winners and Losers Bench Test Results, in PC Power Play Hot Hardware Guide, vol. 2, 75- 75. 1999.

20. Roisin, C. A. Donnelly, L \& Gorman, M. P. Planning and Developing an Interactive Computerised Tutorial for Learning in Higher Education. 4(3). 397-410. 1999.

21. Veal, D. Maj, S. P. \& Swan. Physics: Implications for Computer Technology Education. Proceedings of the 2000 ASEE Conference. Engineering Education Beyond the Millennium. St Louis, MO USA. 2000.

22. Veal, D. and Maj, S. P. Computer and Network Technology Education at Maximum Value and Minimum Cost. Proceedings of the 2000 ASEE Conference. Engineering Education Beyond the Millennium. St Louis, MO USA. 2000.

23. Vygotsky, L. Thought and language. Cambridge, MA USA. MIT Press. 1962.

24. Woodfolk, A. E. Educational Psychology (2ed). Allyn and Bacon. Boston. MA USA. 49-50. 1998.

Proceedings of the 2001 American Society for Engineering Education Annual Conference \& Exposition Copyright C 2001, American Society for Engineering Education 


\section{DAVID VEAL}

David Veal received his honors degree in Theoretical Physics from the University of York in England. After completing a Grad.Dip.Ed. from the University of Keele he lectured in Physics at South Devon College UK for 10 years. He now lives in Western Australia where he has taught Computing and Physics at high school level. $\mathrm{He}$ is a Doctoral student in Computing Science at ECU in Perth, Western Australia. He is investigating competency-based techniques in Computing Science as well as the modeling of computers to aid student understanding.

\section{PAUL MAJ}

Dr S P Maj is a recognized authority in the field of industrial and scientific information systems integration and management. He is the author of a text book, 'The Use of Computers in Laboratory Automation', which was commissioned by the Royal Society of Chemistry (UK). His first book, 'Language Independent Design Methodology - an introduction', was commissioned by the National Computing Centre (NCC). Dr S P Maj has organized, chaired and been invited to speak at many international conferences at the highest level. He has also served on many national and international committees and was on the editorial board of two international journals concerned with the advancement of science and technology. As Deputy Chairman and Treasurer of the Institute of Instrumentation and Control Australia (IICA) educational sub-committee he was responsible for successfully designing, in less than two years a new, practical degree in Instrumentation and Control to meet the needs of the process industries. This is the first degree of its kind in Australia with the first intake in 1996. It should be recognized that this was a major industry driven initiative.

\section{GEOFF SWAN}

Geoff Swan is a physics lecturer at Edith Cowan University in Perth, Western Australia. He mostly teaches first year tertiary physics to science and engineering undergraduates. He received a B.Sc.(Hons). in physics from the University of Adelaide (Australia) in 1984, and a Ph.D. for work in condensed matter physics from the University of Canterbury at Kent (United Kingdom) in 1989. After completing a Grad.Dip.Ed. from the University of Adelaide (Australia) in 1990, Geoff taught physics, general science and mathematics in Australian High Schools for three years. Geoff undertakes research in physics education and is particularly interested in the use of modern technology as it relates to the learning process. 